\title{
Propriedades mecânicas de meniscos frescos de coelhos e preservados em glicerina $98 \%$
}

\author{
Mechanical properties of the fresh rabbit menisci and of the menisci preserved \\ in glycerin $\mathbf{9 8 \%}$
}

\author{
Liana Mesquita Vilela ${ }^{I}$ Ricardo Junqueira Del Carlo ${ }^{I^{*}}$ Rubens Chaves de Oliveira' \\ Mauricio Correia Daltro Rodrigues ${ }^{\mathrm{I}}$ Betânia Souza Monteiro ${ }^{\mathrm{I}}$ Amanda Maria Sena Reis ${ }^{\mathrm{I}}$ \\ Daniel Portela Dias Machado ${ }^{I}$
}

\section{RESUMO}

O presente estudo avaliou a resistência à compressão de meniscos mediais de coelhos da raça Nova Zelândia, por meio de teste mecânico de compressão. Trinta meniscos foram distribuídos em três grupos: grupo MF, composto por dez meniscos frescos; grupo MG, dez meniscos preservados em glicerina 98\%, por 30 dias, e grupo $M R$, dez meniscos preservados em glicerina 98\%, por 30 dias $e$ reidratados em $\mathrm{NaCl} 0,9 \%$, por 12 horas. Os meniscos de cada grupo foram submetidos ao teste de compressão no sentido perpendicular ao seu plano anatômico regular e foram avaliados o limite de elasticidade, a deformação elástica, a tensão ao ponto de ruptura e ao limite de elasticidade e ainda, $o$ índice de rigidez. Os meniscos dos grupos preservados, $M G e$ $M R$, tiveram o limite elástico semelhante ao grupo de meniscos frescos (MF). O grupo de meniscos em glicerina (MG) apresentou menor capacidade de deformação elástica $(P<0,05)$ que os grupos MF e MR, e maior capacidade de sofrer tensão ao limite elástico. Os meniscos do grupo (MG) apresentaram maior rigidez $(P<0,05)$ que os meniscos dos grupos $M F$ e MR. Conclui-se que o grupo de meniscos preservados em glicerina $98 \%$, seguido de reidratação em $\mathrm{NaCl} 0,9 \%$ (MR), não apresentou alterações significativas na capacidade de resistência ao limite elástico dos meniscos.

Palavras-chave: meniscos, resistência mecânica, coelhos.

\section{ABSTRACT}

The present study evaluated the compressive strength of medial menisci of New Zealand rabbits, through mechanical compression test. Thirty menisci were distributed in three groups: group MF, composed by ten fresh menisci; MG group, composed by ten menisci preserved in $98 \%$ glycerin for 30 days; and, group MR, ten menisci preserved in $98 \%$ glycerin for 30 days and rehydrated in $\mathrm{NaCl} 0.9 \%$ for 12 hours. The menisci in each group were submitted to compression test in the perpendicular direction to the anatomical plane and had the elasticity limit, the elastic deformity, the rupture stress point and the stiffness index evaluated. The menisci from the preserved groups $M G$ and $M R$ had the elastic limit similar to the fresh menisci group (MF). The group of menisci preserved in glycerin (MG) presented lower elastic deformity capacity $(P<0.05)$ if compared to the other groups, MF and MR, and $a$ higher tension capacity at elastic limit. The menisci from group $(M G)$ presented higher stiffness $(P<0.05)$ than the ones in the $M F$ and MR groups. It can be concluded that the group menisci preserved in glycerin 98\% followed by rehydration in $\mathrm{Nacl}$ $0,9 \%$ (MR), did not showed any significant alterations in the capacity of the menisci elastic limit.

Key words: meniscus, mechanical resistence, rabbits.

\section{INTRODUÇÃO}

A capacidade da articulação fêmoro-tíbiopatelar (FTP) de realizar flexão, extensão e rotação sobre seu próprio eixo depende da integridade dos músculos, ligamentos, cápsula articular e meniscos, assim como, da interação entre o fêmur, tíbia e patela (VASSEUR, 2007).

Os meniscos são estruturas semilunares interpostas entre as superfícies articulares do fêmur e da tíbia, de vital importância para a boa função e preservação do joelho (BARRET et al., 1998). Atuam na proteção das superfícies articulares opostas, como elementos de transmissão de cargas e de absorção de energia de impacto, contribuem para a estabilidade articular durante a flexão e extensão, ajudando a

'Departamento de Veterinária (DVT), Universidade Federal de Viçosa (UFV), 36570-000, Viçosa, MG, Brasil. *Autor para correspondência. E-mail: ricarlo@ufv.br.

IDepartamento de Engenharia Florestal, Laboratório de Celulose e Papel, UFV, Viçosa, MG, Brasil. 
prevenir movimentos de rotação e a promover estabilidade craniocaudal e vara-valga da articulação (HULSE \& JOHNSON, 2002; GUPTE et al., 2003; TORRES et al., 2006). Além disso, auxiliam na lubrificação da articulação e previnem o atrito da membrana sinovial sobre as superfícies articulares (HULSE \& JOHNSON, 2002).

O menisco medial está aderido firmemente ao ligamento colateral medial e outras estruturas articulares. Devido a estas fortes fixações e às grandes forças que são transmitidas no compartimento medial do joelho, o menisco medial é mais susceptível à lesões (SOLOMON et al., 2001; MCCARTY et al., 2002). É uma fibrocartilagem essencial para o dinamismo do joelho e sua lesão determina o funcionamento anormal da articulação, predispondo a ocorrência de osteoartrite (BAVARESCO, 2003).

No movimento de rotação interna da tíbia, o menisco medial desloca-se em direção cranial e o lateral em direção caudal. Na rotação externa ocorre o movimento inverso, ou seja, acompanham o movimento do fêmur. Isto ocorre devido à ação de tracionamento dos ligamentos patelares e à pressão que o fêmur exerce sobre os meniscos (KAPANDJI, 1990; SOLOMON et al., 2001). Durante a flexão, os meniscos são tracionados caudalmente e durante a extensão cranialmente, conforme suas inserções. Na flexão extrema, a porção caudal do menisco é firmemente comprimida entre a porção posterior do platô tibial e o côndilo femoral (SOLOMON et al., 2001).

A sutura é o tratamento mais recomendado, quando for possível restabelecer a integridade anatômica e funcional do menisco, porém o potencial de cicatrização vai depender da região acometida e sua subsequente irrigação vascular (FABBRICIANI et al., 1997; ANDERSON-MOLINA et al., 2003). Entretanto não é aplicável a todos os casos, somente 30 a $50 \%$ das lesões podem ser reparadas por este método (WIRTH et al., 2002; ANDERSON-MOLINA et al., 2003; FRIEDMAN, 2003). Lesões complexas ou localizadas em áreas avasculares, ou lesões crônicas, geralmente não podem ser reparadas (WYLAND et al., 2002). A sutura meniscal é de difícil realização em cães e gatos devido ao tamanho da articulação. Na última década, com maior aprimoramento das técnicas artroscópicas, algumas rupturas meniscais podem ser suturadas e recuperadas, mesmo assim a avaliação de todo o menisco em cães e gatos pode ser impossível, devido ao restrito espaço articular (FEHR et al., 1996; PIERMATTEI \& FLO, 1999).

Outra técnica é a meniscectomia, que pode ser parcial ou total. A substituição do menisco pode ser considerada quando a meniscectomia total tem que ser feita (HIGUCHI et al., 2000; BUMA et al., 2004; VILELA et al., 2010a). A retirada parcial ou total do menisco está associada, a médio e longo prazo, a processos degenerativos da articulação (RIJK, 2004; VILELA et al., 2010b). A substituição do menisco por um aloenxerto meniscal tem como objetivo evitar o desenvolvimento das alterações degenerativas (CURY et al., 2002; VILELA et al., 2010b) e apresenta como vantagem a possibilidade de utilizar um tecido semelhante em sua morfologia ao tecido que está sendo substituído (BUMA et al., 2004; RECKERS, 2005).

O meio de preservação utilizado, com maior freqüência, para preservação de próteses biológicas é a glicerina $98 \%$. Apresenta como vantagens o baixo custo e a propriedade antisséptica, atuando como bactericida e fungicida (ALVARENGA, 1992; RANDI et al., 2002), além de reduzir a antigenicidade do tecido nela conservado, preservar a textura e aumentar a resistência à tração, sem alterar o grau de elasticidade (PIGOSSI, 1967).

DEL CARLO et al. (1999) e (2007) recomendaram que o enxerto preservado em glicerina deve ser imerso em solução fisiológica estéril acrescida de antibiótico para garantir rehidratação, prevenir contaminações e remover o meio de conservação, antes da enxertia. KRAUSPENHAR (2003) recomendou que o período mínimo de preservação dos enxertos é de 30 dias, pois a eliminação de bactérias gram negativas neste meio pode requerer até 27 dias.

Essa pesquisa teve como objetivo avaliar o efeito da glicerina $98 \%$, sobre a resistência de meniscos de coelhos, por meio de teste mecânico de compressão.

\section{MATERIAL E MÉTODOS}

A metodologia adotada durante o desenvolvimento deste trabalho foi aprovada pela comissão de Ética do Departamento de Veterinária, da Universidade Federal de Viçosa (UFV), sob parecer $n^{\circ}$ 89/2007.

Trinta meniscos mediais foram coletados de 15 coelhos albinos da raça Nova Zelândia, com idade entre três e quatro meses e peso médio de $3 \mathrm{~kg}$, provenientes de criação comercial da cunicultura do Departamento de Zootecnia da Universidade Federal de Viçosa (UFV). A retirada dos meniscos foi realizada imediatamente após o abate e em condições de limpeza, mas sem rigores de assepsia.

Foi realizada incisão transversal na cápsula articular envolvendo o ligamento colateral medial. Um esforço em valgo foi o suficiente para facilitar a visualização e o acesso ao menisco medial. Em seguida, foram seccionados os ligamentos cruzado cranial e 
caudal, meniscotibiais, meniscocapsulares e o intermeniscal, realizando a coleta do menisco medial.

Os meniscos foram acondicionados em frascos de vidro identificados e distribuídos aleatoriamente em três grupos, com dez meniscos cada: grupo MF (grupo controle), foi composto por meniscos recém-coletados, que foram submersos em solução salina ( $\mathrm{NaCl}$ 0,9\%) e imediatamente encaminhados para o laboratório, onde os testes foram realizados; grupo MG, composto por meniscos que foram acondicionados em frascos individuais com a proporção “glicerina 98\%/menisco" de 20:1, por um período de 30 dias, sob temperatura ambiente.

O grupo MR foi composto por meniscos que foram submersos em glicerina 98\%, em frascos individuais, com a proporção "glicerina 98\%/menisco" de 20:1, por um período de 30 dias, sob temperatura ambiente. Após este período, os meniscos foram submersos em solução salina ( $\mathrm{NaCl}$ 0,9\%), durante 12 horas, para reidratação, simulando condições a que seriam submetidos nos períodos pré e trans-operatório. Foi realizado teste de resistência à compressão ao final de cada etapa do experimento, para os três grupos de meniscos - MF, MG e MR.

Os testes foram realizados no Laboratório de Celulose e Papel (LCP) do Departamento de Engenharia Florestal da UFV, em sala climatizada, com umidade relativa do ar de $50 \pm 2 \%$ e temperatura de $23 \pm 1^{\circ} \mathrm{C}$. Utilizou-se o equipamento de aplicação de força Instron modelo 4204 com capacidade da célula de carga de $1000 \mathrm{~N}$, precisão de $\pm 0,2 \mathrm{~N}$ e aquisição de 20 pontos de força e deformação por segundo. A velocidade de aplicação de força ocorreu numa taxa de $25 \mathrm{~mm} \mathrm{~min}^{-1}$ até a ruptura total de cada amostra.

Antes da realização dos testes de compressão, cada menisco foi colocado em uma lâmina de vidro e observado em um microscópio de luz digital, que transmitiu as imagens a um microcomputador, equipado com o software de análise de imagens (ImagePro Plus). As imagens foram capturadas e, posteriormente, a área de cada menisco foi mensurada utilizando o software de análise de imagens, para realização dos cálculos das propriedades: tensão máxima ao ponto de ruptura e tensão ao limite de elasticidade.

O menisco foi então colocado no aparelho, na superfície da barra de compressão inferior, com uma distância de $3 \mathrm{~mm}$ entre as barras superior e inferior (Figura 1). A carga foi aplicada, até as barras ficarem a uma distância de $1 \mathrm{~mm}$, acarretando o esmagamento total da amostra, e o valor da força e deformação ao limite de elasticidade registrado em Newtons e milímetros, respectivamente.
A leitura dos valores das forças aplicadas foi realizada com a utilização de célula de carga e a determinação das deformações foi realizada através do deslocamento da barra de compressão do referido equipamento; ambos conectados a um sistema de aquisição de dados controlados por computador, que permitiu o controle automatizado do sistema responsável pela coleta de dados e derivação das propriedades analisadas. Durante a realização dos testes de compressão foram obtidas relações gráficas relativas às forças aplicadas e as respectivas deformações sofridas pelas amostras. As propriedades avaliadas no decorrer dos testes mecânicos de compressão foram: 1) força ao limite de elasticidade: força absorvida pelo corpo de prova no seu limite máximo de elasticidade, ou seja, até esta força o corpo de prova ainda possui capacidade de retornar à sua estrutura original, sem sofrer deformação permanente (deformação inelástica); expressa em Newton; 2) deformação ao limite de elasticidade: é a deformação sofrida durante a aplicação da força, que desaparece retornando a sua dimensão original, após a retirada desta força; 3) tensão ao limite de elasticidade: é a razão da força ao limite de elasticidade pela área do corpo de prova; 4) tensão ao ponto de ruptura: é a razão da força ao ponto de ruptura pela área do corpo de prova; 5) índice de rigidez (módulo de elasticidade ou módulo de Young): expressa a habilidade do corpo de prova em resistir às deformações em função das tensões aplicadas, expresso em $\left(\mathrm{N} \mathrm{m}^{-2}\right)$. Corresponde à razão da tensão, expressa em $\mathrm{N} \mathrm{m}^{-2}$ pela deformação adimensional até ao limite de elasticidade do corpo de prova. É a medida de rigidez de um material sólido, ou seja, quanto maior, menor é a deformação sofrida pelo material e, portanto, mais o material resiste às forças aplicadas.

As variáveis quantitativas foram submetidas aos testes de Normalidade (Lilliefors) e Homocedasticidade (Cochran) e, posteriormente, à análise de variância. Em caso de significância, foi realizado o teste de Duncan ou de Tuckey, conforme a instabilidade da variável. Quando não atendia às premissas de normalidade e homocesticidade, foram realizadas as transformações apropriadas para posterior análise de variância (SAEG, 1999).

\section{RESULTADOS E DISCUSSÃO}

Força ao limite de elasticidade

A força capaz de deformar o menisco momentaneamente foi estatisticamente semelhante nos três grupos. A média no grupo controle - MF foi de $44,9 \mathrm{~N}$, enquanto nos grupos em glicerina - MG e em 


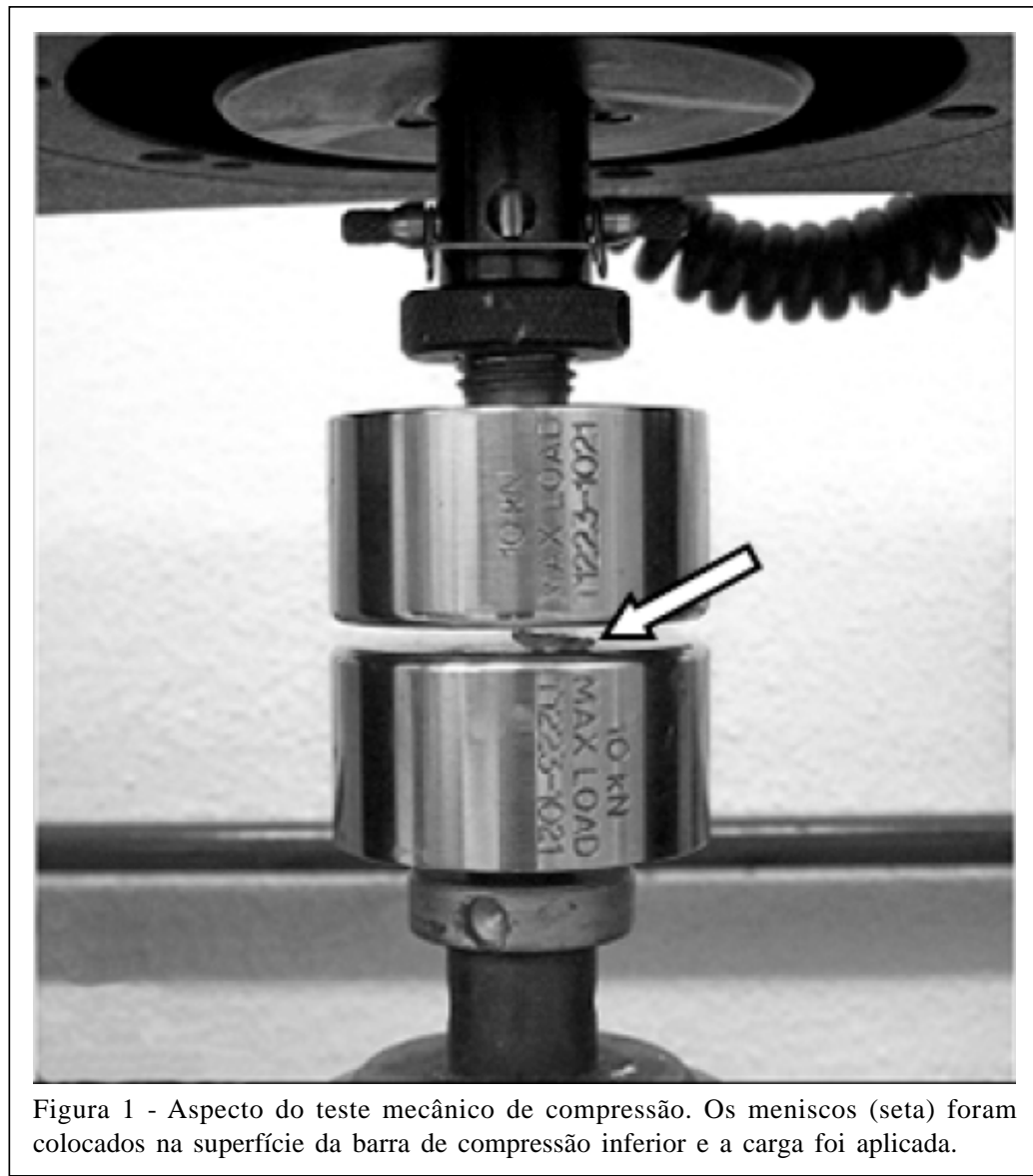

glicerina e reidratados - MR foram de 32,5N e 36,3N, respectivamente (Tabela 1 e Figura 2A); o que significa que os meniscos dos grupos preservados em glicerina - MG e MR e o grupo de meniscos frescos - MF, recémcoletados, tiveram a capacidade de suportar a mesma força ao limite elástico e que o método de preservação não influenciou, negativamente, esta propriedade biomecânica.

Deformação ao limite de elasticidade

A capacidade de deformação reversível foi semelhante entre os grupos de meniscos frescos - MF e de meniscos reidratados - MR, apresentando média de 1,4\% e 1,3\% respectivamente (Tabela 1 e Figura 2B), não havendo diferença significativa entre os dois grupos. No entanto, o grupo de meniscos em glicerina - MG apresentou menor capacidade $(\mathrm{P}<0,05)$ de deformação elástica, média de $0,7 \%$, em relação aos grupos MF e MR.

Isto comprova que a glicerina, ao desidratar o tecido, torna-o mais rígido e com menor capacidade de retornar à sua estrutura original, diminuindo a capacidade de deformação reversível quando submetido a uma força. Entretanto, após a reidratação, em $\mathrm{NaCl}$ 0,9\% - grupo MR, os meniscos readquiriram a capacidade de deformação elástica de forma semelhante aos meniscos frescos - MF. Estes dados conferem importância à reidratação, por 12 horas, para recuperação da função fisiológica. Considera-se ainda que os meniscos são discos fibrocartilaginosos hiperidratados, contendo cerca de 75\% de água, 20\% de fibras colágenas, além de glicosaminoglicanos, condrócitos e pequena quantidade de fibras elásticas (BUMA et al., 2004). Desta forma, admite-se que a solução de $\mathrm{NaCl}$ 0,9\% recuperou a capacidade de deformação elástica dos meniscos do grupo MR, sendo esta propriedade estatisticamente semelhante à dos meniscos frescos. Os meniscos preservados em glicerina e reidratados - MR, não perderam a capacidade de deformação elástica, que é uma propriedade desejável nos meniscos, pois atuam como amortecedores, transmitindo cargas e absorvendo energia de impacto (HULSE \& JOHNSON, 2002; TORRES et al., 2006). 
Tabela 1 - Valores médios e desvios padrão obtidos no teste mecânico de compressão no grupo menisco fresco - MF e nos grupos preservados - MG e MR.

\begin{tabular}{llccl}
\hline Grupo & F.Lim.Elas. & Def.Lim.Elas. & Tens.Lim.Elas. & Tens.P.Rup. \\
\hline MF & $44,9 \pm 11,7$ & $1,4 \pm 0,3$ & $577,8 \pm 175,5$ & $1215,7 \pm 239,3$ \\
MG & $32,5 \pm 9,7$ & $0,7 * \pm 0,2$ & $695,6 \pm 175,9$ & $2123,4 * \pm 392,6$ \\
MR & $36,3 \pm 10,1$ & $1,3 \pm 0,3$ & $719,9 \pm 203,1$ & $1134,4 \pm 212,1$ \\
\hline
\end{tabular}

F.Lim.Elas.= força ao limite de elasticidade (N);

Def.Lim.Elas.= deformação ao limite de elasticidade (\%);

Tens.Lim.Elas.= tensão ao limite de elasticidade (Kpa);

Tens.P.Rup.= tensão ao ponto de ruptura $(\mathrm{KPa})$;

Índ.Rig.= índice de rigidez (Mpa).

Médias seguidas de asteriscos nas colunas são estatisticamente diferentes, segundo teste de Tuckey ou Duncan (P<0,05).

Tensão ao limite de elasticidade

Constatou-se que nos três grupos experimentais, a tensão ao limite de elasticidade suportado foi semelhante, não havendo diferença significativa entre eles. No grupo controle, a média foi de $577,8 \mathrm{KPa}$, e nos grupos tratados foram de $695,6 \mathrm{KPa}$ nos meniscos em glicerina e 719,9KPa nos meniscos reidratados (Tabela 1 e Figura 2C). A glicerina não alterou a capacidade dos meniscos preservados suportarem tensão quando submetidos a uma força capaz de promover deformação elástica.

Tensão ao ponto de ruptura

O grupo MG apresentou tensão ao ponto de ruptura média de $2123,4 \mathrm{KPa}$, sendo significativamente maior que nos grupos MF e MR, que obtiveram médias de 1215,7KPa e 1134,4KPa, respectivamente; estes últimos foram semelhantes, não havendo diferença entre eles (Tabela 1 e Figura 3A). O grupo MG apresentou capacidade de sofrer maior tensão no momento da ruptura, provavelmente em razão da desidratação e conseqüente alteração de forma e diminuição de tamanho dos meniscos, tornando-os estruturas menos elásticas, mais densas e rígidas. Características estas inapropriadas aos meniscos que atuam como estruturas móveis e elásticas, promovendo a congruência entre o fêmur e a tíbia (HULSE \& JOHNSON, 2002).

Índice de rigidez

A média e desvio padrão do índice de rigidez foi de 44,9MPa $\pm 9,6 ; 127,6 \mathrm{MPa} \pm 19,7$ e 51,1MPa $\pm 9,6$ para os grupos MF, MG e MR, respectivamente (Tabela $1 \mathrm{e}$ Figura 3B). Os meniscos do grupo MG apresentaram, significativamente $(\mathrm{P}<0,05)$, maior índice de rigidez do que os meniscos dos grupos MF e MR. Isto ocorreu, provavelmente, pela desidratação promovida pela glicerina, diminuindo a elasticidade dos meniscos.

Após reidratação, o grupo MR apresentou índice de rigidez semelhante ao dos meniscos frescos -
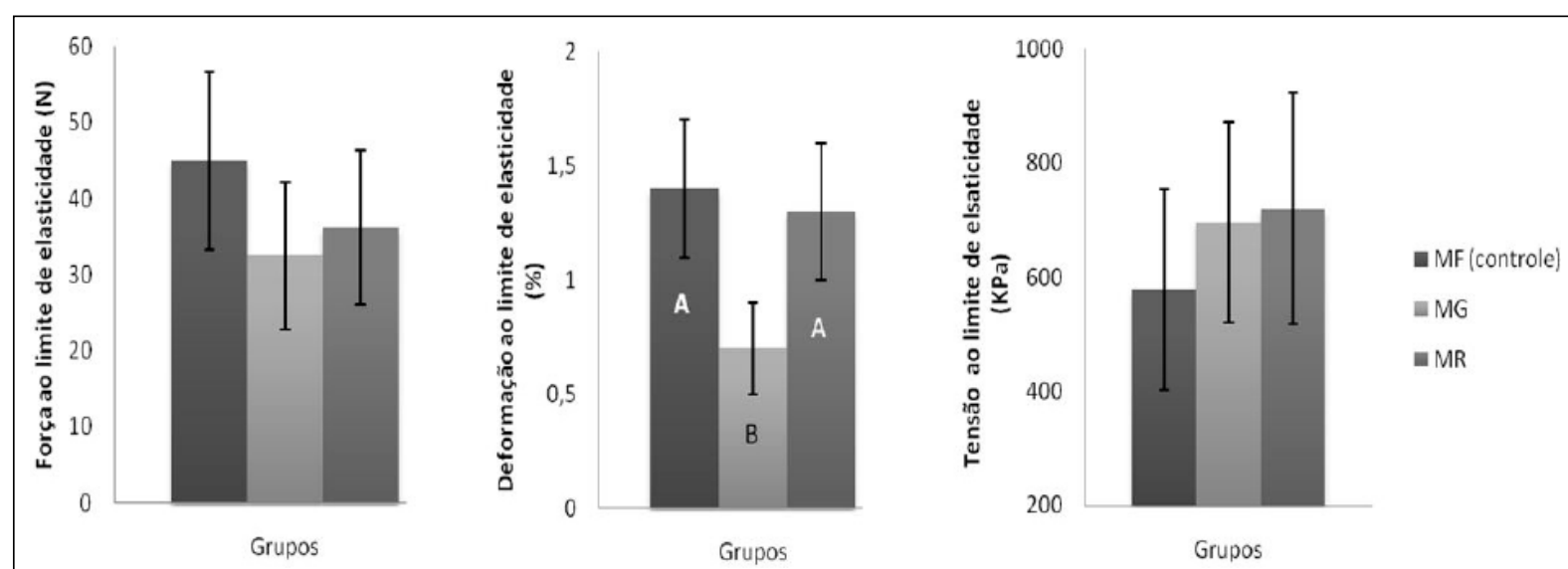

Figura 2 - Representação dos valores médios da força (A), deformação (B) e tensão (C) ao limite de elasticidade, obtidos nos meniscos frescos - MF, meniscos preservados em glicerina - MG e meniscos preservados em glicerina e reidratados - MR. Em (A e C) os tratamentos não diferem entre si e em (B) os tratamentos seguidos de uma mesma letra não diferem entre si ao nível de $5 \%$ de probabilidade. 


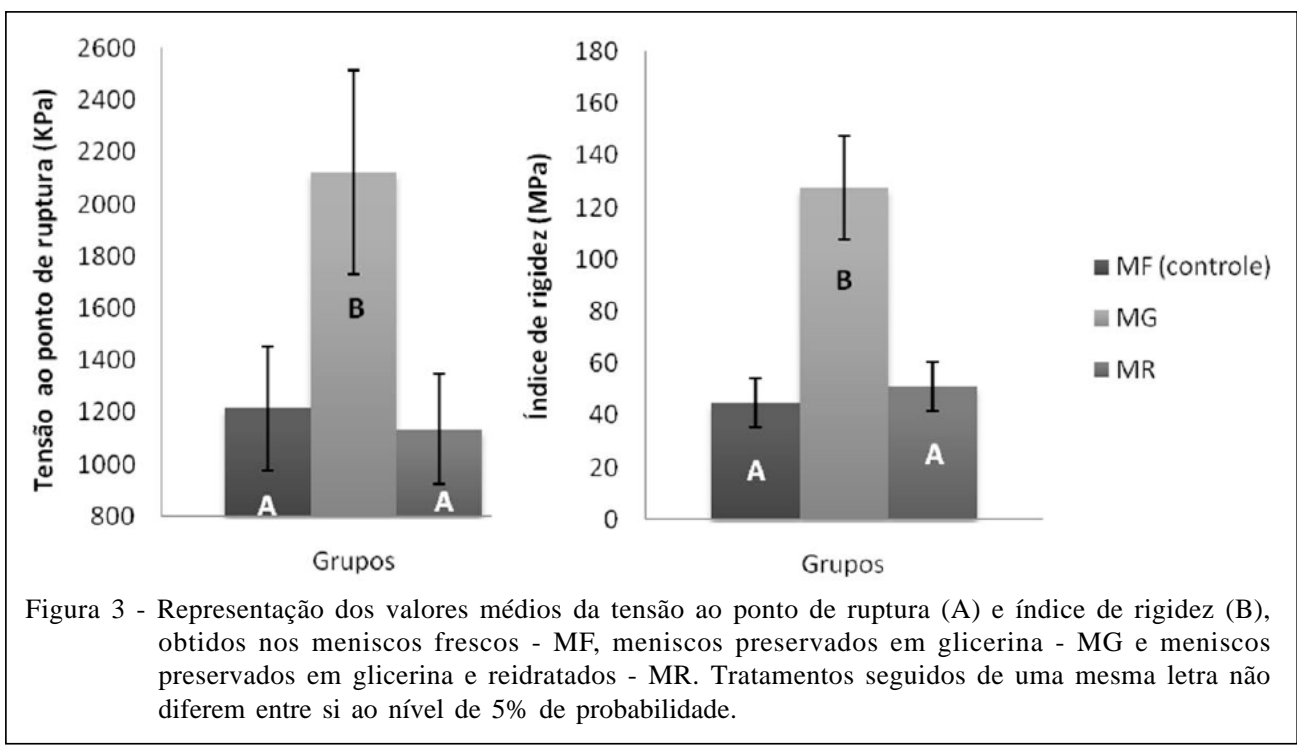

MF. A reidratação, em $\mathrm{NaCl}$ 0,9\%, por 12 horas, foi suficiente para diminuir a rigidez, aumentando assim a capacidade elástica dos meniscos.

Ressalte-se que quanto maior o índice de rigidez, menor é a deformação (elasticidade) sofrida pelo material e, portanto, mais o material resiste às forças nele aplicadas.

A lesão do menisco geralmente está associada à instabilidade articular causada pela ruptura do LCCr (SMITH et al., 2002; RECKERS et al., 2005), tornando importante a inspeção da integridade dos meniscos durante a cirurgia reparadora de meniscos. Desta forma, procedimentos cirúrgicos do joelho que não apresentam resultados satisfatórios, podem ter como causa agravante uma doença articular degenerativa e progressiva em função de uma lesão meniscal não tratada.

As propriedades mecânicas de meniscos frescos de coelhos e preservados em glicerina 98\%, avaliadas pela metodologia preconizada nesta pesquisa permitem sugerir que futuros estudos devem ser conduzidos para testar a eficácia clínica da aplicação de aloenxertos meniscais.

\section{CONCLUSÃO}

Conclui-se que a glicerina $98 \%$ causa rigidez e conseqüente redução da capacidade elástica (capacidade deformável) de meniscos de coelhos, quando preservados em glicerina $98 \%$, durante 30 dias. Nos meniscos preservados em glicerina $98 \%$ por 30 dias, seguido de reidratação em $\mathrm{NaCl} 0,9 \%$ por 12 horas, a glicerina não provoca alterações significativas no limite elástico, mantendo-os semelhantes aos meniscos frescos.

\section{REFERÊNCIAS}

ALVARENGA, J. Possibilidades e limitações da utilização de membranas biológicas preservadas em cirurgia. In: DALECK, C.R. et al. Tópicos em cirurgia de cães e gatos. Jaboticabal: FUNESP-UNESP, 1992. Cap.2, p.33-42.

ANDERSSON-MOLINA, H. et al. Arthroscopic partial and total meniscectomy: a long-term follow-up study with matched controls. Arthroscopy, v.18, p.183-189, 2003. Disponível em: <http://linkinghub.elsevier.com/retrieve/pii/ S0749806302919973>. Acesso em: 20 mar. 2010. doi:10.1053/jars.2002.30435.

BARRET, G.R. et al. Clinical results of meniscus repair in patients 40 years and older. Arthroscopy, v.14, p.824-829, 1998. Disponível em: <http://www.sciencedirect.com/science/ a r t i c l e / B 6 W B 8 - 4 H G 6 P 3 N - 8 / 2/ 8390f97d13a94a69d7510958292d5b4d>. Acesso em: 15 mar. 2010. doi:10.1016/S0749-8063(98)70018-0.

BAVARESCO, F.L. Evolução de um paciente submetido à meniscectomia parcial: estudo de caso. 2003. 46f. Trabalho de Conclusão de Curso apresentado à Universidade Estadual do Oeste do Paraná - UNIOESTE, Cascavel, PR. Disponível em: <http://www.unioeste.br/projetos/elrf/ monografias/2003/mono/15.pdf>. Acesso em: 18 mar. 2010.

BUMA, P. et al. Tissue engineering of the meniscus. Biomaterials, v.25, n.9, p.1523-1532, 2004. Disponível em: <http://www.sciencedirect.com/science/article/B6TWB49D2CPP-3/2/873104bd90e5fa56c989aa84e111cb89>. Acesso em: 12 mar. 2010. doi:10.1016/S0142-9612(03)00499-X.

CURY, R.P.L. et al. Transplante homólogo de menisco: estudo experimental em coelhos. Revista Brasileira de Ortopedia e Traumatologia, v.37, n.8, p.341-350, 2002. Disponível em: <http://www.rbo.org.br/materia.asp?idIdioma=1\&mt=783>. Acesso em: 20 mar. 2010. 
DEL CARLO, R.J. et al. Aloenxertos ósseos caninos diferentemente preservados. Revista Brasileira de Ciência Veterinária, v.6 n.3, p.121-126, 1999.

DEL CARLO, R.J. et al. Integração de aloenxertos ósseos corticais associados ou não à células-tronco da medula óssea, proteína óssea morfogenética (BMP) e autoenxerto esponjoso em cães. Veterinária e Zootecnia, v.14, p.204-215, 2007. Disponível em: <http://www.fmvz.unesp.br/revista/volumes/ vol14_n2/Revista\%20v14n02_2007_66_77.pdf >. Acesso em: 12 mar. 2010.

FABBRICIANI, C. et al. Meniscal allografts: cryopreservation vs deep-frozen technique. An experimental study in goats. Knee Surgery, Sports Traumatology, Arthroscopy, v.5, p.124134, 1997. Disponível em: <http://www.springerlink.com/ content/w0ru9g7pa929tyvr/>. Acesso em: 15 mar. 2010. doi: $10.1007 / \mathrm{s} 001670050038$.

FEHR, M. et al. Arthroscopic studies of the stifle of dogs. Tierarztliche Praxis, v.24, n.2, p.137-143, 1996.

GUPTE, C.M. et al. The meniscofemoral ligament. Veterinary and Comparative Orthopaedics and Traumatology, v.16, p.26-31, 2003.

HIGUCHI, H. et al. Factors affecting long-term results after arthroscopic partial meniscectomy. Clinical Orthopaedics and Related Research, v.377, p.161-168, 2000.

HULSE, D.A.; JOHNSON, A.L. Tratamento da doença articular. In: FOSSUM, T.W. Cirurgia de pequenos animais. São Paulo: Rocca, 2002. Cap.30, p.1076-1077.

KAPANDJI, I.A. Fisiologia articular. São Paulo, Manole, 1990. 296p.

KRAUSPENHAR, L.C. Viabilidade bacteriana no meio de conservação glicerina $\mathbf{9 8 \%}$ do tendão calcâneo comum. 2003. 62f. Dissertação (Mestrado em Cirurgia Veterinária) Universidade Federal de Santa Maria, RS.

MCCARTY, E.C. et al. Meniscus repair: considerations in treatment and update of clinical results. Clinical Orthopaedics and Related Research, v.402, n.1, p.122134, 2002.

PIERMATTEI, D.L.; FLO, G.L. A articulação fêmuro-tíbiopatelar (joelho). In: PIERMATTEI, D.L.; FLO, G.L. Manual de ortopedia e tratamento das fraturas dos pequenos animais. 3.ed. São Paulo: Manole, 1999. Parte III, cap.17, p. 480-538.

PIGOSSI, N. Glicerina na conservação de dura-mater. Estudo experimental. 1967. 86f. Dissertação (Livre Docência) - Universidade de São Paulo, São Paulo, SP.
RANDI, F.E. et al. Aplicabilidade e métodos de conservação de próteses biológicas. Unimar Ciências, v.11, n.1/2, p.39-44, 2002.

RECKERS, L.J. et al. Effects of different preservation temperatures and periods menisci cellularity in rabbits. Acta Cirúrgica Brasileira, v.20, n.6, p.428-432, 2005. Disponível em: <http:// www.scielo.br/scielo.php?script=sci_arttext\&pid=S010286502005000600006\&lng=en\&nrm=iso>. Acesso em 21 mar. 2010. doi: 10.1590/S0102-86502005000600006.

RIJK, P.C. Meniscal allograft transplantation - Part I: background, results, graft selection and preservation, and surgical considerations. Arthroscopy, v.20, n.7, p.728-743, 2004. Disponível em: <http:/www.sciencedirect.com/science/article/ B6WB8-4D8F5K5-S/2/a660ee9d553c1b5d6a5faa8950acb01a>. Acesso em: 18 mar. 2010. doi: 10.1016/j.arthro.2004.06.015.

SAEG. Sistema para análises estatísticas e genéticas. Versão 8.1. Viçosa: Fundação Arthur Bernardes, Universidade Federal de Viçosa, 1999.

SMITH, G.N. et al. Severity of medial meniscus damage in the canine knee after anterior cruciate ligament transection. Osteoarthritis and Cartilage, v.10, n.4, p.321-326, 2002. Disponível em: <http://www.sciencedirect.com/science/article/ B6WP3-45KND4H-B/2/0f1a08c9d89a814a7e6944068c2c37f4>. Acesso em: 17 mar. 2010. doi: 10.1053/joca.2002.0520.

SOLOMON, D.H. et al. The rational clinical examination. Does this patient have a torn meniscus or ligament of the knee? Value of the physical examination. Journal of the American Medical Association, v.286, n.13, p.1610-1620, 2001. Disponível em: <http://jama.ama-assn.org/cgi/content/abstract/ 286/13/1610> Acesso em: 20 mar. 2010.

TORRES, B.B.J. et al. Como proceder nas lesões meniscais em cães - Revisão. Clínica Veterinária, n.63, p.48-58, 2006.

VASSEUR, P.B. Articulação do joelho. In: SLATTER, D. Manual de cirurgia de pequenos animais. 3.ed. São Paulo: Manole, 2007. V.2, cap.147, p.2090-2115.

VILELA, L.M. et al. Estrutura e celularidade de meniscos frescos de coelhos (Oryctolagus cuniculus) e preservados em glicerina. Pesquisa Veterinária Brasileira, v.30, n.4, p.295-300, 2010a.

VILELA, L.M. et al. Avaliação das fibras colágenas de meniscos frescos e preservados em glicerina: estudo experimental em coelhos (Oryctolagus cuniculus). Pesquisa Veterinária Brasileira, v.30, n.4, p.321-327, 2010b. 